\title{
Optimization of Alkali Treatment Condition on Tensile Properties of Kenaf Reinforced Polyester Composite Using Response Surface Method
}

\author{
Ezazul Fahmee Ahmad Jamal, Mohd Yusni Hashim, Mohd Hilmi Othman*, \\ Omar Mohd Faizan Marwah, Azriszul Mohd Amin, Muhammad Akmal Johar \\ and Ng Chuan Huat
}

Faculty of Mechanical Engineering \& Manufacturing, Universiti Tun Hussein Onn Malaysia, 86400 Parit Raja, Johor, MALAYSIA.

Received 26 July 2017; accepted 22 January 2018, available online 24 April 2018

\begin{abstract}
The interface bonding from the chemical treatment of the reinforced fibers can be seen as a great factor that affecting the mechanical properties of fiber composite. The alkali treatment serves as a method to increase the surface roughness that are resulting in better mechanical interlocking and increases the amount of cellulose exposed on the fiber surface. The optimum condition of the alkali treatment on the tensile strength was investigated using response surface method (RSM). The kenaf fiber was treated with different concentration of alkali treatment, soaking time and temperature. Then, the prepared samples of fiber composites were tested using ASTM D638 tensile test to determine the tensile strength. The highest average reading of kenaf reinforced composite was $26.37 \mathrm{MPa}$ from the highest percentage of volume fraction which was $25 \%$. The analysis of variance was conducted using the full quadratic term at the beginning of response surface methodology analysis work. From the response surface plot, the optimum composite tensile strength was achieved by setting the immersion temperature ranging at $30^{\circ} \mathrm{C}$ to $80^{\circ} \mathrm{C}$ and alkali concentration of $6 \%$. The values of this experimental tensile strength can be used for light weight constructional applications, auto industry, and many custom products.
\end{abstract}

Keywords: Alkali treatment, kenaf fiber composite, response surface method

\section{Introduction}

Natural fibers are materials in a raw form that originated from a hairlike frame, extracted from vegetables, creature or mineral source and convertible into non-woven textures, for example, felt or paper and woven fabric. The reinforced fiber included a procedure of blending or refining the normal fibers to shape a high quality composite strand with groups of polymer materials. The common types of reinforced fibers used are carbon, fiberglass, aramid, boron, regular filaments and others polymer composites. Reinforced composite materials can be sorted into two principal classifications as short reinforced fiber materials and continuous reinforced fiber materials. Continuous reinforced materials will regularly constitute a layered or covered structure. The woven and persistent fiber styles are normally accessible in an assortment of structures, being pre-impregnated with the given framework (sap), dry, unidirectional tapes of different widths, plain weave, silks, meshed, and sewed. The advantages of natural fibers compared to other materials have given numerous interest for scientific researchers. This is due to its advantages such as environmentally friendly, abundant availability, fully biodegradable, renewable and have low density. It is also having a high performance in terms of mechanical properties and low in cost where it fulfills the economic interest in large areas of industries [1].

Although it is used in large areas of engineering, the fibers have a few weaknesses compared to synthetic fibers. This is because of the poor wettability, incompatibility with certain polymer matrices and have high moisture absorption. These weaknesses can be overcome by physical treatment such as cold plasma treatment and also chemical treatment by using isocyanates and sodium hydroxide permanganate [1].

There are several factors that leads to the vast usage of natural fiber in scientific researches due to the awareness of environmental issue, the fluctuation price of natural fuel and also the optimization of natural resource consumption. All of the plant fibers contain cellulose as their major structural component, whereas the animal fibers mainly consist of protein [2]. Despite of these advantages, there are several drawbacks from the application of natural fibers in reinforced composite. Even though that mineral-based natural fibers exist within the vast group of minerals and were once used extensively in composites, these are currently avoided due to associated health issues [3]. One of that drawbacks is the moisture absorption cellulose fibers can cause the swelling in the 
fiber that leads to degradation in mechanical properties. The kenaf fibers are difficult to manually separate and visually disperse evenly during manufacturing [4]. One of the methods to solve this problem is using the chemical treatment and the most commonly used in this treatment is sodium hydroxide $(\mathrm{NaOH})$ as the alkali treatment. Stress transfer from the matrix to the fiber takes place at such interphase and, therefore, it is important to characterize its properties to better understand the performance of the composite. The mechanical properties of the natural fibers are primarily influence from its particular size, shape and quality [5]. Studies suggest that agro-based fibers are a viable alternative to inorganic/material based reinforcing fibers in commodity fiber-thermoplastic composite materials as long as the suitable processing conditions are used and for applications where higher water absorption may be so critical [6-7]. Regular fibers that have been used have great possibility for support yet they must be reasonably treated to raise their properties on the offchance that they are to be utilized as a part of specialized engineering or everyday applications [8-9]. Physical and synthetic techniques can be connected depending of what change that need to be accomplished, and since normal fibers have individual sources and become under various climatic conditions, the need to locate an appropriate strategy for alteration cannot be overemphasized [10]. The fact that it causes less impact on the environment is proven since natural fiber can be recycled thermally. Therefore, according to good mechanical properties, the usages of the natural fibers were retained in all sorts of applications. [11]. Composite fibers with combination with thermoplastic materials are being used in a variety of application such as mass transit, automotive and military structures. It is shown that natural fibers have recently become attractive to the automotive industry as an alternative reinforcement for glass fiber reinforced thermoplastics [12].

Therefore, based on these previous findings and problem statements, the objectives of this paper are:

a) To analyze the effect of alkali treatment towards the tensile strength of kenaf fiber reinforced composites.

b) To determine the main effect contribution.

c) To optimize the condition of the alkali treatment on the tensile strength by using analysis of variance and response surface methods (RSM)

\section{Materials and methods}

The material and methods detailing the usage of fibers and polymers, with thorough explanation regarding the alkali treatment, tensile test and response surface method.

\subsection{Materials}

The fiber material for the study is kenaf fiber that was given by Kenaf Natural Fiber Industries (Malaysia) Sdn. Bhd. The fiber that was received was in a long strip and then was cut at the length with the range of $3 \mathrm{~mm}-5 \mathrm{~mm}$ long. The polymer resin used for this project was polyester. The kind of polyester picked are Polyester 2697-1 which are non-waxed polymer resin with low density. The density of polyester resin was set at $1.098 \times 10^{-3} \mathrm{~g} / \mathrm{mm}^{3}$. This resin is known to have good mechanical strength, great rigidity, impact resistance and also extraordinary toughness.

\subsection{Alkali treatment}

The chemical solution for the alkali treatment are Sodium Hydroxide $(\mathrm{NaOH})$ in the form of small pellets. The kenaf fiber was treated with $4 \%$ (weight/volume) for 24 hours at $20{ }^{\circ} \mathrm{C}$. The treated fiber was then dried in an oven for 24 hours at the temperature of $36{ }^{\circ} \mathrm{C}$. The kenaf fiber was then being washed and flushed with water for a couple of times until the $\mathrm{pH}$ estimation of the fiber become $7.0 \pm 0.5 \mathrm{pH}$. At that point, the kenaf will dried utilizing microwave Labtec HT-Steamer for an hour [1].

The processes are repeated using 6 and $8 \%$ (weight/volume) with the soaking time of 36 and 48 hours, the soaking temperature of 40 and $60{ }^{\circ} \mathrm{C}$ and the drying temperature of 45 and $54^{\circ} \mathrm{C}$, respectively. The kenaf fiber was then measured in the fabrication process after it dried. The measurement of weight was calculated with the 'rule of mixture' between the polymer and the kenaf fiber, which was a $20 \%$ volume for the kenaf fiber [1].

\subsection{Composite preparation}

The procedure of blending is performed based on the 'Rules of Mixture' from the proportion of polyester and the kenaf fiber. The kenaf fiber was blended with polyester resin with $20 \%$ proportion of kenaf fiber. After that, the fiber and polyester are washed a few times and dried for 24 hours. The treated kenaf, and polyester mixture will be hot-pressed into a square-shape form to create a composite with $3 \mathrm{~mm}$ thickness and placed on a level plate and isolated uniformly after it is chopped finely with a paint scraper. The vacuum machine will be used to suck out the trapped air in the composite if necessary. Then, the mold is coated with silicon to ease the process of removing the mixture from the mold. The mixture will be pressed at a weight of $2 \mathrm{MPa}$ for 10 minutes. The cemented blend is squeezed again with a block and leave at the room temperature for 5 to 6 hours [1].

\subsection{Tensile test}

The tensile strength of fiber composite measured by using Universal Testing Machine GT-7001-LS10 from the ASTM D638 standard. The examples are cut into a 'dogbone' shape and twenty (20) examples are tested with the crosshead speed of $2 \mathrm{~m} / \mathrm{s}$ at room temperature condition.

\subsection{Response surface method}

The response surface method analysis was carried out by running the experiment with highest efficiency, using an appropriate decision of design, plan, and to decide working conditions on an arrangement of controllable factors that offer ascent to an ideal reaction. The key to RSM are created utilizing straight polynomial models, for the most part first-degree and second degree models, with consistent reaction factors accepted, to be independent and 
normally distributed with consistent error variances [1314]. Jiménez-Contreras et al. summarized that, the RSM is an accumulation of scientific and mathematical methods that displaying and investigation of issues in which a reaction of intrigue is affected by a few factors and the target is to optimize the reaction [15].

The levels of input variables, $\mathrm{x}_{1}, \mathrm{x}_{2}$, and $\mathrm{x}_{3}$, which maximize the yield $[\mathrm{y}]$ of the process, then the process yield is stated as:

$$
y=f\left(x_{1}, x_{2}, x_{3}\right)+\varepsilon
$$

where $\varepsilon$ represents the noise or error observed in the response $\mathrm{y}$. If the expected response is denoted by $\mathrm{E}[\mathrm{y}]=$ $\mathrm{f}\left[\mathrm{x}_{1}, \mathrm{x}_{2}, \mathrm{x}_{3}\right]=\eta$, then the surface represented by $\eta=\mathrm{f}\left[\mathrm{x}_{1}\right.$, $\left.\mathrm{x}_{2}, \mathrm{x}_{3}\right]$ is called a response surface. The ' $\mathrm{x} 1$ ' denoted as the alkali solution concentration, the ' $\mathrm{x} 2$ ' denotes as the soaking time, and ' $\mathrm{x} 3$ ' denotes as the soaking temperature used in this study. The alkali treatment time and fiber volume percentage that effecting the tensile strength could be obtained through the depiction of the response surface plot. The highest value of tensile strength was recorded at $27 \mathrm{MPa}$ at 6 hours alkali treatment time. 95\% confidence level of tensile strength can be predicted from the quadratic model based on the response surface method plot.

\section{Results and Discussion}

The results and discussion explaining the data gained from the experiment with proper discussion about the effect of alkali treatment towards the strength of composite with optimization details such as the main interaction analysis, regression model and analysis of variance.

\subsection{Kenaf fiber tensile strength}

The data from kenaf fiber tensile strength experiment varies with the changes of alkali treatment condition that include the weight-over-volume ratio and also the soaking temperature of the alkali solution. Table 1 shows the result of kenaf fiber tensile strength (MPa) average values prior to the alkali treatment conditions and temperature level that have been applied.

The alkali concentrations were carried out in 4,6 , and 8 weight-over-volume percentage at room temperature, 60 and $100{ }^{\circ} \mathrm{C}$ for 30,240 , and 480 minutes. It is observed that from Table 4.1, 4\% alkali concentration gave highest average tensile strength value at room temperature for all 30,240 , and 480 minutes soaking time at values of 522.89 , 498.85 , and $444.67 \mathrm{MPa}$. The data represent the uniform decrement of tensile strength when the alkali concentration and the time being increased.

Previous research [4] had stated in their finding that 6 $\% \mathrm{NaOH}$ treated specimens gave superior ultimate tensile strength values as compared to others. When the $\mathrm{NaOH}$ concentration is increased to $6 \%$, an approximation of $0.4 \%$ increment is noticed for both maleated polyethylene and maleated polypropylene cases. This was explained by the increment of uniformity that yields to the enhancement in strength, due to the removal of the impurities. However, the trend was decreased when the concentration of $\mathrm{NaOH}$ was increased up to $9 \%$ due to high concentration applied that yields to damage the fibers inter-laminar bonding.

\subsection{Composite tensile strength}

The tensile strength testing on this project was conducted according to ASTM D638-10 standard. 20 pieces of specimen were selected for different alkali treatment condition which include the soaking time and soaking temperature. The effect of alkali treatment conditions on composite kenaf fiber was determined by selecting a suitable range of alkali treatment factors. The factors include the alkali concentration (w/v \%), soaking time (minute), and immersion temperature $\left({ }^{\circ} \mathrm{C}\right)$.

From the data collected, the mean value of composite tensile strength was $26.55 \mathrm{MPa}$. The value was higher than the untreated kenaf fiber polyester composite and unreinforced polyester tensile strength, which were 23.74 $\mathrm{MPa}$ and $15.51 \mathrm{MPa}$ accordingly. At $25 \%$ kenaf fiber volume fraction, it was found that alkali treated kenaf fiber polyester composite tensile strength was increased $11.84 \%$ than untreated kenaf fiber polyester composite. Previous researchers [16] have reported that the tensile properties such as tensile strength and modulus of elasticity also show considerable increases as the volume fraction of the fiber increases. The tensile strength at the break for the neat epoxy composites around $30 \mathrm{MPa}$. Other researchers [17], stated in the study that the mechanical tensile strength 21.25 MPa for kenaf fiber reinforced composite. These numbers represent the experimental result of this study did not defer largely in terms of number for tensile strength values with other researchers.

\subsection{Main effect and interaction analysis for tensile strength}

Figure 1 shows the representation of the main effect plot for kenaf fiber tensile strength at different conditions of alkali treatment. The main effect plot shows that alkali concentration gave a higher magnitude followed by immersion time and temperature. The increasing the variable level and decreasing of kenaf fiber tensile strength indicates that all of three factors show negative main effect. Between all the factors, the alkali concentration shows a largest magnitude change compared to immersion duration and temperature factors. This plot shows the highest kenaf fiber tensile strength was obtained at low alkali concentration. Kenaf fiber tensile strength value continued to decrease when alkali concentration is increased. A similar result was presented in immersion duration and temperature factors. However, both factors show less slope changed on kenaf fiber tensile strength, particularly in the temperature range from $60^{\circ} \mathrm{C}$ to $100^{\circ} \mathrm{C}$. It's suggested that, both effect magnitudes were less than alkali concentration. Interaction plot for alkali concentration and immersion time shows parallel lines that indicate there was no interaction existed between the parameters as shown in Figure 2. A similar pattern was presented in alkali concentration and immersion temperature interaction plot. There is a possibility of interaction in the immersion time and temperature 
interaction plot at longer time if the temperature were extended. If a pattern was statistically significant, then an appropriate test was required.

Table 1. The result of kenaf fiber tensile strength $(\mathrm{MPa})$ average values prior to the alkali treatment conditions and temperature level

\begin{tabular}{|c|c|c|c|c|c|c|c|c|c|c|}
\hline \multirow{4}{*}{$\begin{array}{l}\text { Kenaf } \\
\text { fiber } \\
\text { tensile } \\
\text { strength } \\
(\mathrm{MPa})\end{array}$} & \multirow{4}{*}{$\begin{array}{l}\text { Time } \\
(\mathrm{min})\end{array}$} & \multicolumn{9}{|c|}{ Temperature Level $\left({ }^{\circ} \mathrm{C}\right)$} \\
\hline & & \multicolumn{3}{|c|}{$\begin{array}{l}\text { Room temperature } \\
\text { (Approximately 27) }\end{array}$} & \multicolumn{3}{|c|}{60} & \multicolumn{3}{|c|}{100} \\
\hline & & \multicolumn{9}{|c|}{ Alkali Concentration (w/v \%) } \\
\hline & & 4 & 6 & 8 & 4 & 6 & 8 & 4 & 6 & 8 \\
\hline Average & 30 & 522.89 & 429.24 & 314.53 & 506.02 & 364.36 & 308.58 & 492.87 & 401.92 & 300.28 \\
\hline Average & 240 & 498.85 & 414.82 & 318.70 & 490.38 & 363.81 & 308.58 & 419.04 & 337.76 & 277.63 \\
\hline Average & 480 & 444.67 & 354.32 & 291.59 & 398.41 & 297.65 & 272.43 & 413.86 & 323.78 & 249.19 \\
\hline
\end{tabular}

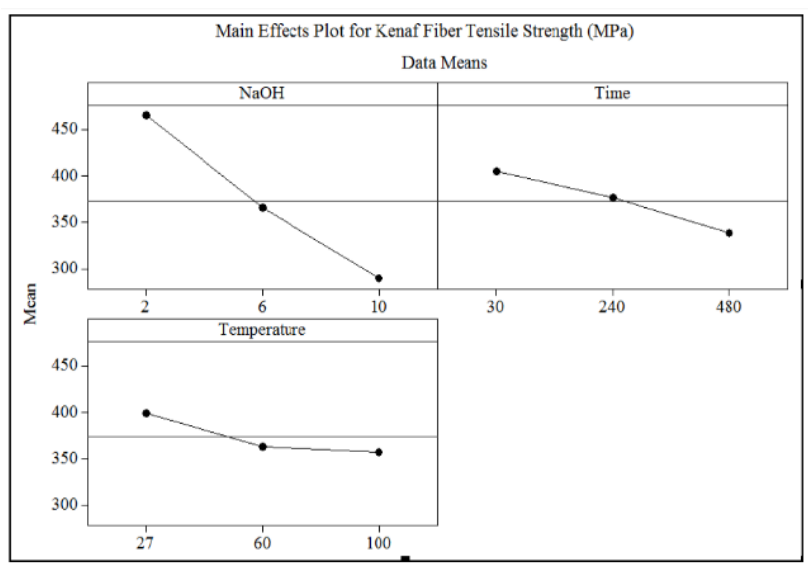

Fig. 1 The main effect plot for kenaf fiber tensile strength.

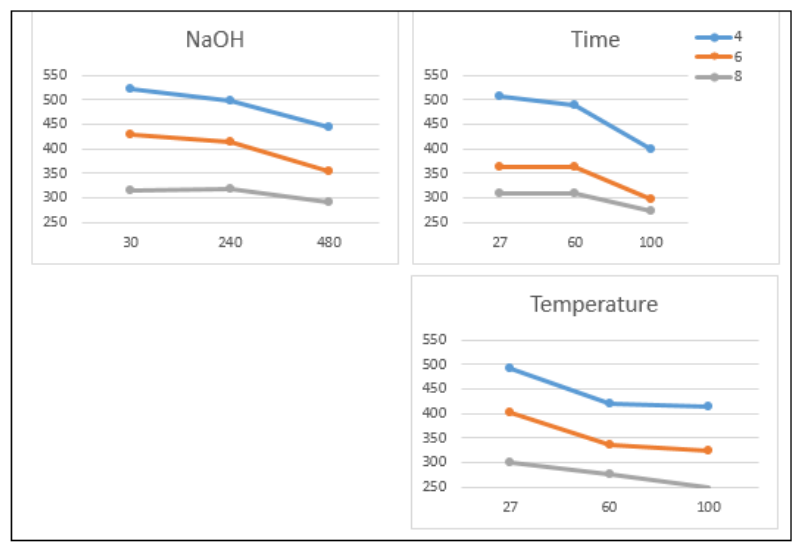

Fig. 2 Interaction plot of kenaf fiber tensile strength at different alkali treatment conditions.

From Table 2, it shows that for three-way interaction term $(\mathrm{NaOH} \times$ Time $\mathrm{x}$ Temperature) and all two-way interaction term, the $p$ value was bigger than $0.05(>0.05)$, which show that all these terms was insignificant. All terms were considered as significant due to the $p$ value was less than 0.05 for main effect term. This ANOVA results show good agreement with results obtained from interaction plot and the main effect plot. The regression equation of kenaf fiber tensile strength was generated with consideration of these significant terms.

\subsection{Regression model for tensile strength}

To determine the effect of alkali treatment conditions on tensile strength of short randomly oriented kenaf fiber polyester composite, kenaf fiber was treated with alkali at specific conditions.

The experimental result using analysis of variance was conducted using a full quadratic term at the beginning of response surface methodology analysis work. The regression model $F$ ratio was 62.41 with $p$ value $=0.000$. Since the $\mathrm{p}$ value was smaller than 0.05 as alpha, $\alpha$ value, at least one of the regression variables contribute significantly to the regression model was concluded.

The sources with a $\mathrm{p}$ value less than $5 \%(<0.05)$ were significant and stated as significant, whereas the sources with a $\mathrm{p}$ value bigger than $5 \%(>0.05)$ was stated as insignificant. A regression model was further broken into different orders of term in the model (linear, square and interaction) [14]. In linear terms, alkali concentration $(\mathrm{p}=$ $0.052)$ and immersion time $(\mathrm{p}=0.885)$ was bigger than 0.05 which indicated these factors were not significant. In square terms, all factors were significant $(p<0.05)$, indicating that there is curvature in the response surface. In interaction terms, only time by temperature interaction was less than 0.05 .

Table 3 shows the ANOVA table after all the insignificant terms being removed. For linear terms, alkali $(p=0.054)$ and time $(p=0.886)$, the effect shows the $p$ value bigger than 0.05 . However, all the square and interaction term $p$ value was less than $0.05(<0.05)$, indicating all these terms were significant. The lack of fit having an $\mathrm{F}$ value of 1.87 with a $11.8 \%$ chance of occurrence was considered to be as insignificant. The insignificant lack of fit from that percentage is suitable for a model to be considered as reliable. For composite tensile strength result, $91.3 \%$ of the variation in tensile was explained by the regression model, the predicted R2 was $88.4 \%$, and the adjusted R2 was $90.1 \%$. Because of the R2 and adjusted R2 values are too close to each other, it indicated that there were no- 
insignificant terms have been added in the regression model.

As a result, the regression model for composite tensile strength of different alkali treatment setting using experimental data in uncoded units was generated as follows:

$\hat{\mathrm{YTS}}=24.0763+0.3536 \mathrm{X}_{1}+0.0098 \mathrm{X}_{2}+0.0321 \mathrm{X}_{3}-$ $0.0277 \mathrm{X}_{12}-1.6091 \mathrm{E}-05 \mathrm{X}_{22}-2.3665 \mathrm{E}-04 \mathrm{X}_{32}-$ $2.4921 \mathrm{E}-05 \mathrm{X}_{2} \mathrm{X}_{3}$

where alkali concentration $(\mathrm{w} / \mathrm{v} \%)$ is $\mathrm{X} 1$, immersion duration (minute) is $\mathrm{X} 2$ and immersion temperature $\left({ }^{\circ} \mathrm{C}\right)$ is $\mathrm{X} 3$. Linear, square and interaction terms were included in this regression equation.

Figure 3 shows the contour and response surface plot of predicted composite tensile strength versus alkali concentration and immersion temperature at a constant time. The immersion temperature was plotted on the Xaxis and alkali concentration was plotted on the $\mathrm{Y}$-axis. The contour areas represent constant responses, which correspond to composite tensile strength. The contour with the darkest green color in the center area and left side of the $\mathrm{X}$-axis indicates the contour where composite tensile strength is the highest $(>27.2 \mathrm{MPa})$.
In response surface plot, the composite tensile strength can be maximized by setting the immersion temperature at $30^{\circ} \mathrm{C}$ to $80^{\circ} \mathrm{C}$ and alkali concentration range from $4 \mathrm{w} / \mathrm{v} \%$ to $8.5 \mathrm{w} / \mathrm{v} \%$ setting. From these settings, composite tensile strength is predicted to become a maximum value at the center of the range for the $\mathrm{X}$-axis and $\mathrm{Y}$-axis. The composite tensile strength decreases if immersion temperature and alkali concentration shifted from the center point of the maximum range.

The findings of this project could be useful for further research. For instance, a research about blending bamboo fibre with polymer nanocomposite had been carried out and the processing condition had been optimized [18]. However, there was no investigation had been carried out about the effect of bamboo fibre treatment towards this blend. As for another research about using coconut coir as the packaging material [19-20], the effect of fibre treatment towards the properties of the packaging material should be beneficial and recommended. Furthermore, instead of tensile strength, other mechanical behavior such as fracture mechanism could be carried out to reveal the toughening condition before and after the alkali treatment

Table 2 ANOVA table for kenaf fiber tensile strength at different alkali treatment conditions

\begin{tabular}{|c|c|c|c|c|c|}
\hline Source & $\mathrm{DF}$ & $\begin{array}{l}\text { Sum of } \\
\text { Squares }\end{array}$ & $\begin{array}{c}\text { Mean } \\
\text { Squares }\end{array}$ & $\mathrm{F}$ & $\mathrm{P}$ \\
\hline $\mathrm{NaOH}$ & 2 & 421743 & 210872 & 97.4 & 0.000 \\
\hline Time & 2 & 59427 & 29713 & 13.72 & 0.000 \\
\hline Temperature & 2 & 27169 & 13584 & 6.27 & 0.004 \\
\hline $\mathrm{NaOH}^{*}$ Time & 4 & 6741 & 1685 & 0.78 & 0.544 \\
\hline $\mathrm{NaOH}^{*}$ Temperature & 4 & 4444 & 1111 & 0.51 & 0.726 \\
\hline Time*Temperature & 4 & 5530 & 1382 & 0.64 & 0.637 \\
\hline $\mathrm{NaOH}^{*}$ Time*Temperature & 8 & 6838 & 855 & 0.39 & 0.919 \\
\hline Error & 54 & 116912 & 2165 & & \\
\hline Total & 80 & 648804 & & & \\
\hline $\mathrm{S}=46.5299$ & & & $\mathrm{R}-\mathrm{Sq}=81.98 \%$ & & $\mathrm{R}-\mathrm{Sq}(\operatorname{adj})=73.30 \%$ \\
\hline
\end{tabular}


Table 3 The ANOVA table for composite tensile strength at different alkali treatment conditions after eliminating insignificant

\begin{tabular}{|c|c|c|c|c|c|}
\hline Source & $\mathrm{DF}$ & Sum of Squares & Mean Squares & $\mathrm{F}$ & $\mathrm{p}$ \\
\hline Regression & 7 & 30.011 & 4.287 & 78.060 & 0.000 \\
\hline Linear & 3 & 0.974 & 0.325 & 5.910 & 0.002 \\
\hline $\mathrm{NaOH}$ & 1 & 0.213 & 0.213 & 3.880 & 0.054 \\
\hline Time & 1 & 0.001 & 0.001 & 0.020 & 0.886 \\
\hline Temp & 1 & 0.759 & 0.759 & 13.820 & 0.000 \\
\hline Square & 3 & 28.032 & 9.344 & 170.140 & 0.000 \\
\hline $\mathrm{NaOH} * \mathrm{NaOH}$ & 1 & 18.859 & 1.622 & 29.530 & 0.000 \\
\hline Time*Time & 1 & 8.353 & 5.474 & 99.680 & 0.000 \\
\hline Temp*Temp & 1 & 0.820 & 0.820 & 14.930 & 0.000 \\
\hline Interaction & 1 & 1.005 & 1.005 & 18.310 & 0.000 \\
\hline Time*Temp & 1 & 1.005 & 1.005 & 18.310 & 0.000 \\
\hline Residual Error & 52 & 2.856 & 0.055 & & \\
\hline Lack-of-Fit & 7 & 0.632 & 0.090 & 1.830 & 0.105 \\
\hline Pure Error & 45 & 2.224 & 0.049 & & \\
\hline Total & 59 & 32.867 & & & \\
\hline \multicolumn{2}{|c|}{$\mathrm{R}-\mathrm{Sq}=91.31 \%$} & \multicolumn{2}{|c|}{$\mathrm{R}-\mathrm{Sq}($ pred $)=88.42 \%$} & \multicolumn{2}{|c|}{$\mathrm{R}-\mathrm{Sq}(\operatorname{adj})=90.14 \%$} \\
\hline
\end{tabular}

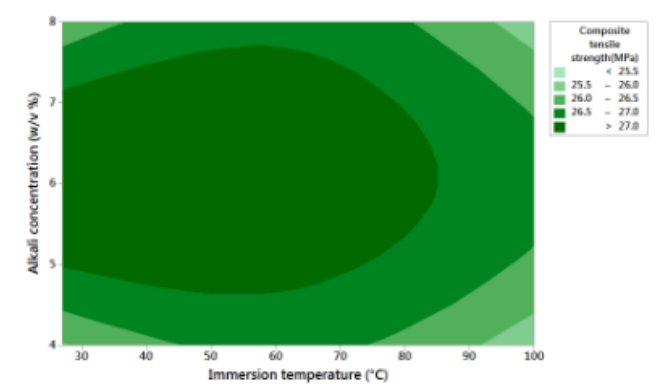

(a) Contour plot

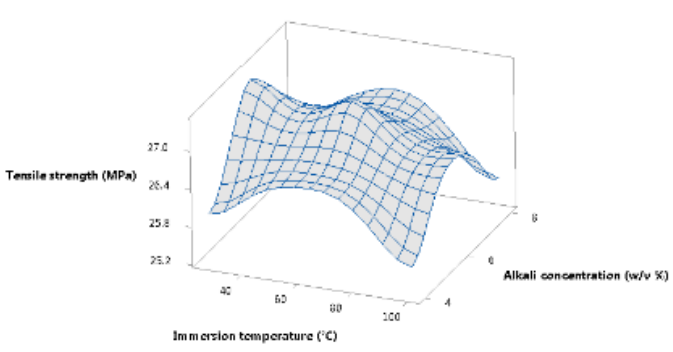

(b) Response surface plot

Fig. 3 Contour and response surface plot of predicted composite tensile strength versus alkali concentration and immersion temperature.

\section{Summary}

Based on the data obtained, the alkali $(\mathrm{NaOH})$ treatment gave effect to the tensile strength of kenaf fiber reinforced composite. The alkali treatment improved the tensile strength of the kenaf fiber reinforced composite in the scope of mechanical properties. The untreated kenaf fiber shows the lowest value of tensile strength which is 18.454 MPa and 25\% treated kenaf fiber gave the highest value which is $23.7 \mathrm{MPa}$. The value has proved that the treatment reduces the hydrophilicity characteristic of kenaf fiber that may be turned off for improved fiber matrix interface bonding.

As for the main effect on alkali treatment conditions determination in this project, it is clearly shows contribution on the kenaf fiber mechanical properties which in this case, tensile strength. The kenaf fiber tensile strength shows a descending pattern with the increasing of alkali treatment condition at all conditions. All of the alkali concentration, soaking time, and soaking temperature gives a significant interaction effect of kenaf fiber composite. Based on the parameter condition of kenaf fiber, the plot on main effect show the decreasing value of tensile when all the parameters' values is being increased.

Analysis of variance was conducted using full a quadratic term at the beginning of response surface methodology analysis work. From the response surface plot, it is observed that the composite tensile strength can be maximized by setting the immersion temperature at $30^{\circ} \mathrm{C}$ to $80^{\circ} \mathrm{C}$ and alkali concentration range of $6 \%$ setting. 
From these settings, composite tensile strength is predicted to become a maximum value at the center of the range for the $\mathrm{X}$-axis and $\mathrm{Y}$-axis. The composite tensile strength decreases if immersion temperature and alkali concentration shifted from the center point of the maximum range. The values of this experimental tensile strength can be used by lightweight constructional applications, auto industry, and many custom products.

\section{References}

[1] Hashim, M. Y., Roslan, M. N., Amin, A. M., Zaidi, A. M.A., and Ariffin, S., Mercerization treatment parameter effect on natural fiber reinforced polymer matrix composite: A brief review. World academy of science, engineering and technology, Volume 68, (2012), pp. 1638-1644.

[2] Ochi, S., Mechanical properties of kenaf fibers and kenaf/PLA composites. Mechanics of materials, 40(4), (2008), pp. 446-452.

[3] Pickering, K. L., Efendy, M. A., and Le, T. M., A review of recent developments in natural fibre composites and their mechanical performance. Composites Part A: Applied Science and Manufacturing, Volume 83, (2016), pp. 98-112.

[4] Meon, M. S., Othman, M. F., Husain, H., Remeli, M. F., and Syawal, M. S. M. Improving tensile properties of kenaf fibers treated with sodium hydroxide. Procedia Engineering, Volume 41, (2012), pp. 15871592.

[5] Herrera-Franco, P., and Valadez-Gonzalez, A., A study of the mechanical properties of short naturalfiber reinforced composites. Composites Part B: Engineering, Volume 36(8), (2005), pp. 597-608.

[6] Sumaila, M., Amber, I., and Bawa, M., Effect of fiber length on the physical and mechanical properties of ramdom oriented, nonwoven short banana (musabalbisiana) fiber/epoxy composite. Cellulose, Volume 62, (2013), pp.64.

[7] Kabir, M. M., Wang, H., Lau, K. T., and Cardona, F., Chemical treatments on plant-based natural fibre reinforced polymer composites: An overview. Composites Part B: Engineering, Volume 43(7), (2012), pp. 2883-2892.

[8] Nishino, T., Hirao, K., Kotera, M., Nakamae, K., and Inagaki, H., Kenaf reinforced biodegradable composite. Composites Science and Technology, Volume 63(9), (2003), pp.1281-1286.

[9] Nitta, Y., Noda, J., Goda, K., and Lee, W. I., Effect of alkali-treatment on tensile properties of kenaf long fibers. Proceeding of the 18th International Conference on Composite Materials. (2011), pp. 1-5
[10] Adekunle, K. F., Surface treatments of natural fibers - a review: Part 1. Open Journal of Polymer Chemistry, Volume 5(03), (2015), pp. 41.

[11] Abdullah, A. H., Alias, S. K., Jenal, N., Abdan, K., and Ali, A. Fatigue behavior of kenaf fibre reinforced epoxy composites. Engineering Journal, Volume 16(5), (2012), pp. 106-13.

[12] Ghani, M. A. A., Salleh, Z., Hyie, K. M., Berhan, M. N., Taib, Y. M. D., and Bakri, M. A. I., Mechanical properties of kenaf/fiberglass polyester hybrid composite. Procedia Engineering, Volume 41, (2012), pp.1654-1659.

[13] Balakrishna, A., Rao, D. N., and Rakesh, A. S., Characterization and modeling of process parameters on tensile strength of short and randomly oriented Borassus Flabellifer (Asian Palmyra) fiber reinforced composite. Composites Part B: Engineering, volume 55, (2013), pp. 479-485.

[14] Penjumras, P., Abdul Rahman, R., Talib, R. A., and Abdan, K., Response surface methodology for the optimization of preparation of biocomposites based on poly (lactic acid) and durian peel cellulose. The Scientific World Journal, Volume 2015, (2015), pp. 112.

[15] Jiménez-Contreras, E., Torres-Salinas, D., Moreno, R., Baños, R., and López-Cózar, E., Response Surface Methodology and its application in evaluating scientific activity. Scientometrics, Volume 79(1), (2008), pp. 201-218.

[16] Saba, N., Paridah, M. T., and Jawaid, M., Mechanical properties of kenaf fibre reinforced polymer composite: A review. Construction and Building materials, Volume 76, (2015), pp. 87-96.

[17]El-Shekeil, Y. A., Sapuan, S. M., Khalina, A., Zainudin, E. S., and Al-Shuja'a, O. M., Influence of chemical treatment on the tensile properties of kenaf fiber reinforced thermoplastic polyurethane composite. eXPRESS Polymer Letters, Volume 6(12) (2012), pp. 1032-1040

[18] Othman, M. H., Hasan, S., Khamis, S. Z., Ibrahim, M. H. I., and Amin, S. Y. M., Optimisation of Injection Moulding Parameter towards Shrinkage and Warpage for Polypropylene-Nanoclay-Gigantochloa Scortechinii Nanocomposites. Procedia Engineering, Volume 184, (2017), pp.673-680.

[19] Othman, M.H., Main, N.M., Kunchi Mon, S.Z., and Mohamad, Z., Development of Paper Using Coir Fibers as a Packaging Product. Asian Journal of Scientific Research, Volume 6(2), (2013), pp. 207216.

[20] Othman, M. H., Hasan, S., and Ibrahim, M. Z., The Effects of Water Content towards the Packaging Properties of Paper Made from Coconut Coir. Applied Mechanics and Materials, Volume 315, (2013), pp. 161-165. 